\title{
Preoperative thyroid hormone levels predict ICU mortality after cardiopulmonary bypass in congenital heart disease patients younger than 3 months old
}

\author{
Di Yư ${ }^{\dagger}$ Liang Zou ${ }^{\dagger}$, Yueshuang Cun, Yaping Li, Qingfeng Wang, Yaqin Shu* and Xuming Mo*
}

\begin{abstract}
Background: We aimed to study the effectiveness of preoperative thyroid hormone levels in predicting intensive care unit (ICU) mortality after cardiopulmonary bypass (CPB) in infants with congenital heart disease (CHD).

Methods: We retrospectively reviewed and analyzed data from 133 patients younger than 3 months old who underwent cardiac surgery with CPB from June 2017 to November 2019. ICU mortality prediction was assessed by multivariate binary logistic regression analysis and area under the curve (AUC) analysis.

Results: Non-survivors were younger ( $17.46 \pm 17.10$ days vs. $38.63 \pm 26.87$ days, $P=0.006)$, with a higher proportion of neonates ( $9 / 13$ vs. 41/120, $P=0.017$ ) and a higher proportion of individuals with a Risk Adjustment for Congenital Heart Surgery-1 (RACHS-1) score $\geq 4$ (8/13 vs. 31/120, $P=0.020)$. No significant difference was found in CPB and aortic cross-clamping (ACC) time. The levels of free triiodothyronine (FT3) (3.91 $\pm 0.99 \mathrm{pmol} / \mathrm{L}$ vs. $5.11 \pm$ $1.55 \mathrm{pmol} / \mathrm{L}, P=0.007)$ and total triiodothyronine (TT3) $(1.55 \pm 0.35 \mathrm{nmol} / \mathrm{L} \mathrm{vs} .1 .90 \pm 0.57 \mathrm{nmol} / \mathrm{L}, P=0.032)$ were higher in survivors than in non-survivors. In the ICU mortality prediction assessment, FT3 was an independent mortality predictor and showed a high AUC (0.856 \pm 0.040$)$.

Conclusions: The preoperative FT3 level was a powerful and independent predictor of ICU mortality after CPB in infants with CHD younger than 3 months old.
\end{abstract}

Keywords: Thyroid hormone, Congenital heart disease, Mortality

\section{Background}

Congenital heart disease (CHD) is the most common congenital malformation among live births, accounting for approximately one-third of birth defects [1]. A systematic review showed that the prevalence of CHD increased from $0.6 \%$ in the 1930 s to $9.1 \%$ at the end of the 20th century [2]. Cardiopulmonary bypass (CPB) is often used for surgery in complex CHD cases. However,

\footnotetext{
* Correspondence: shu_dd@163.com; mohsuming15@njmu.edu.cn ${ }^{+} \mathrm{Di}$ Yu and Liang Zou these authors are contributed equally to this work. Department of Cardiothoracic Surgery, Children's Hospital of Nanjing Medical University, Jiangdong South No. 8 Road, 210008 Nanjing, China
}

hemodilution, hypothermia and ultrafiltration during $\mathrm{CPB}$ have been shown to induce a temporary hypothyroid state, especially in infants $[3,4]$.

The thyroid hormones triiodothyronine (T3) and thyroxin (T4) have permissive effects on $\beta 1$-adrenergic receptors, which enhance heart contractility and reduce systemic vascular resistance [5, 6]. Additionally, thyroid hormones increase preload and decrease afterload, leading to increased cardiac output [7]. Several studies have shown that the hypothyroid state, which affects the myocardial energy metabolism, is associated with poor prognosis after cardiac surgery with CPB $[8,9]$.

(c) The Author(s). 2021 Open Access This article is licensed under a Creative Commons Attribution 4.0 International License, which permits use, sharing, adaptation, distribution and reproduction in any medium or format, as long as you give appropriate credit to the original author(s) and the source, provide a link to the Creative Commons licence, and indicate if changes were made. The images or other third party material in this article are included in the article's Creative Commons licence, unless indicated otherwise in a credit line to the material. If material is not included in the article's Creative Commons licence and your intended use is not permitted by statutory regulation or exceeds the permitted use, you will need to obtain permission directly from the copyright holder. To view a copy of this licence, visit http://creativecommons.org/licenses/by/4.0/ The Creative Commons Public Domain Dedication waiver (http://creativecommons.org/publicdomain/zero/1.0/) applies to the data made available in this article, unless otherwise stated in a credit line to the data. 
Correspondingly, thyroid hormone replacement therapy could provide clinical benefits in infants undergoing CPB [10-12].

A study was conducted to assess the effects of $\mathrm{CPB}$ on thyroid function in infants weighing less than $5 \mathrm{~kg}$, and the results showed that low $\mathrm{T} 3$ and $\mathrm{T} 4$ levels were both predictors of high mortality [13]. Talwar et al. [14] found that low postoperative total T4 (TT4) levels were correlated with postoperative morbidity, a prolonged postoperative course, and prolonged mechanical ventilation (MV) in open heart surgery with CPB. Since thyroid hormone levels play a critical role in recovery from cardiac surgery and thyroid hormones decrease after $\mathrm{CPB}$, the preoperative level of thyroid hormones could be a predictor of intensive care unit (ICU) mortality after CPB in $\mathrm{CHD}$ patients. Therefore, we conducted a retrospective study to evaluate the effect of preoperative thyroid hormone levels in relation to survival in patients after cardiac surgery with $\mathrm{CPB}$.

\section{Methods}

We retrospectively reviewed the medical records of patients with CHD younger than 3 months old in our hospital between June 2017 and November 2019. This study protocol was approved by the Institutional Ethical Committees of the hospital (201912257-1). We excluded patients who were older than 90 days at the time of surgery, patients without $\mathrm{CPB}$, patients with primary thyroid gland disease, and patients with trisomy 21 syndrome. Clinical data included gender; age; weight; Risk Adjustment for Congenital Heart Surgery-1 (RACHS-1) score [15]; type of CHD; preoperative serum albumin level (normal range: 40-55 g/L); preoperative thyroid hormone levels [total T3 (TT3, normal range: 1.29$3.11 \mathrm{nmol} / \mathrm{L}$ ), free T3 (FT3, normal range: $2.8-7.1 \mathrm{pmol} /$ L), TT4 (normal range: $66-187.4 \mathrm{nmol} / \mathrm{L}$ ), free T4 (FT4, normal range: $12.1-22 \mathrm{pmol} / \mathrm{L}$ ), thyroid stimulating hormone (TSH, normal range: $0.2-5 \mu \mathrm{IU} / \mathrm{ml})$ ], which is a routine examination for patients with $\mathrm{CHD}$ in our clinic; $\mathrm{CPB}$ time; aortic cross-clamping (ACC) time; and ICU mortality.

\section{Statistical analysis}

The statistical analysis was performed with SPSS version 20.0 software (Chicago, IL, USA). Continuous variables are expressed as the mean \pm standard deviation, while categorical variables are summarized as frequencies and percentages. Comparisons between groups were performed using an unpaired Student's t-test for continuous variables and a $x^{2}$ or Fisher's exact test for categorical variables. Multivariate binary logistic regression analysis was further conducted to assess the independent ICU mortality predictors. Receiver operating characteristic (ROC) curves were generated to examine the ability of variables to predict ICU mortality, and the area under the curve (AUC) was calculated from the ROC curve. Youden's index, which maximizes the sum of the sensitivity and specificity, was used to define the optimal cutoff value. Statistical significance was defined as $P<0.05$.

\section{Results \\ Patient characteristics}

This study enrolled 133 patients younger than 3 months old (with a mean age of $36.56 \pm 26.78$ days), including 50 neonates $(37.6 \%)$. Eleven patients were premature, and their age was adjusted according to their gestational age. Among the participants, 39 patients $(29.3 \%)$ had a RACHS-1 operative risk score $\geq 4$. Based on the normal ranges mentioned above, 10(7.5\%), 1(0.8\%), 23(17.3\%), $2(1.5 \%)$ and $48(36.1 \%)$ patients had low FT3, low FT4, low TT3, low TT4 and high TSH levels, respectively. A total of 13 patients $(9.8 \%)$ died in the ICU; their causes of death were low cardiac output syndrome $(8 / 133$, $6.0 \%)$, sepsis $(3 / 133,2.3 \%)$, and brain injury $(2 / 133$, $1.5 \%)$. The demographic and physiological characteristics of the patients are presented in Table 1.

\section{Comparison of the survivor and non-survivor groups}

Compared with survivors, non-survivors were younger $(17.46 \pm 17.10$ days vs. $38.63 \pm 26.87$ days, $P=0.006)$, were more likely to be neonates $(9 / 13$ vs. $41 / 120, P=$ 0.017), and had a higher proportion of RACHS-1 scores $\geq 4(8 / 13$ vs. $31 / 120, P=0.020)$, but there was no significant difference in preoperative serum albumin levels. The CPB and ACC time were slightly longer in the non-survivors, but no significant difference was found compared with the survivors. The non-survivors had low levels of FT3, FT4, TT3 and TT4 and a high $\mathrm{TSH}$; however, the FT3 $(3.91 \pm 0.99 \mathrm{pmol} / \mathrm{L}$ vs. $5.11 \pm$ $1.55 \mathrm{pmol} / \mathrm{L}, P=0.007)$ and TT3 $(1.55 \pm 0.35 \mathrm{nmol} / \mathrm{L}$ vs. $1.90 \pm 0.57 \mathrm{nmol} / \mathrm{L}, P=0.032$ ) levels showed a significant difference between survivors and non-survivors. Interestingly, all non-survivors were male (Table 2).

\section{Independent predictors of ICU mortality}

Predictors with a P-value less than 0.1, except gender, were included in the multivariate binary logistic regression analysis to determine the independent predictors of ICU mortality. As shown in Table 3, FT3 was an independent predictor of mortality.

\section{Value of FT3 in predicting ICU morality}

ROC curves were constructed to examine the performance of FT3 as a predictor of ICU mortality (Fig. 1). The AUC was $0.856 \pm 0.040$, the optimal cutoff value was 
Table 1 Characteristics of enrolled patients with congenital heart disease

\begin{tabular}{|c|c|}
\hline Characteristic & All patients $(n=133)$ \\
\hline Age (days) & $36.56 \pm 26.78$ \\
\hline$\leq 28$ days & $50(37.6 \%)$ \\
\hline$>28$ days and $\leq 90$ days & $83(62.4 \%)$ \\
\hline \multicolumn{2}{|l|}{ Gender } \\
\hline Male & $89(66.9 \%)$ \\
\hline Female & $44(33.1 \%)$ \\
\hline Weight (kg) & $3.89 \pm 0.91$ \\
\hline \multicolumn{2}{|l|}{ RACHS-1 } \\
\hline Score-1 & $4(3.0 \%)$ \\
\hline Score-2 & $46(34.6 \%)$ \\
\hline Score-3 & $44(33.1 \%)$ \\
\hline Score-4 & $38(28.6 \%)$ \\
\hline Score-5 & $1(0.7 \%)$ \\
\hline Score-6 & $0(0 \%)$ \\
\hline \multicolumn{2}{|l|}{ Type of Surgery } \\
\hline ASD & $2(1.5 \%)$ \\
\hline VSD & $12(9.0 \%)$ \\
\hline VSD + ASD & $50(37.6 \%)$ \\
\hline COA/IAA & $15(11.3 \%)$ \\
\hline TAPVC & $21(15.8 \%)$ \\
\hline TGA & $19(14.3 \%)$ \\
\hline PA-VSD & $3(2.2 \%)$ \\
\hline DORV & $2(1.5 \%)$ \\
\hline Other & $9(6.8 \%)$ \\
\hline \multicolumn{2}{|l|}{ Operative factors } \\
\hline CPB time (min) & $114.23 \pm 81.98$ \\
\hline ACC time (min) & $46.03 \pm 21.59$ \\
\hline ICU mortality & $13(9.8 \%)$ \\
\hline Preoperative serum albumin (g/L) & $38.23 \pm 4.87$ \\
\hline \multicolumn{2}{|l|}{ Preoperative thyroid function } \\
\hline FT3 (pmol/L) & $4.99 \pm 1.54$ \\
\hline FT4 (pmol/L) & $21.28 \pm 5.82$ \\
\hline TT3 (nmol/L) & $1.87 \pm 0.56$ \\
\hline TT4 (nmol/L) & $120.25 \pm 34.61$ \\
\hline TSH $(\mu \mid \mathrm{l} / \mathrm{ml})$ & $5.72 \pm 5.95$ \\
\hline
\end{tabular}

RACHS-1 Risk Adjustment in Congenital Heart Surgery-1, ASD atrial septal defect, VSD ventricular septal defect, COA coarctation of aorta, IAA interrupter aortic arch, TAPVC total anomalous pulmonary venous connection, TGA transposition of the great arteries, PA pulmonary atresia, DORV double outlet right ventricular, $C P B$ cardiopulmonary bypass, $A C C$ aortic crossclamping, FT3 free triiodothyronine, FT4 free thyroxin, $\Pi \pi 3$ total triiodothyronine, $T \pi 4$ total thyroxin, $T S H$ thyroid stimulating hormone
$4.89 \mathrm{pmol} / \mathrm{L}$, and the sensitivity and specificity were $100 \%$ and $63.3 \%$, respectively (Table 4 ).

\section{Discussion}

To the best of our knowledge, the present study is the first clinical retrospective analysis of the predictive value of preoperative thyroid hormone levels in patients with CHD undergoing $\mathrm{CPB}$. In our study of 133 consecutive patients, we found that FT3 may be an independent predictor of ICU mortality based on multivariate binary logistic regression and ROC curve analyses. Previous studies [16] have reported that a low T3 level was an independent predictor of ICU mortality, which is consistent with our finding. However, for CHD patients, especially children, RACHS-1 scores could predict ICU mortality, length of ICU stay and duration of MV [17-20]. In our study, compared with survivors, non-survivors had higher RACHS-1 scores. However, in the additional multivariate binary logistic regression analysis, the RACHS-1 score was not an independent mortality predictor. We suggest that RACHS-1 scores on the basis of CHD subtype should not consider the relationship of year, weight, and levels of thyroid hormone as confounding factors [21]. Additionally, the small sample size of children with RACHS- 1 scores of 5 or 6 may be another reason for the reduced statistical power. Although the $\mathrm{CPB}$ and ACC time were high in nonsurvivors, no significant difference was found compared with survivors, which demonstrates the improvement of cardiac surgery techniques and perfusion mode of $\mathrm{CPB}$ in China.

We found an interesting phenomenon in our study, namely, that all of the non-survivors were male. This could be related to the preference for sons over daughters, which is very common in China. Thus, when a child is diagnosed with complex CHD, based on the gender, operative risk and economic status of the parents, girls may not have the opportunity to undergo the operation, especially in rural areas [22, 23]. However, gender showed significant association with ICU mortality, but considering the gender selective bias, we removed gender from the multivariate binary logistic regression.

Thyroid hormones have important effects on the cardiovascular system, such as increasing cardiac output and decreasing systemic vascular resistance, which are predictive of good outcomes [24, 25]. However, several studies have verified that cardiac surgery with $\mathrm{CPB}$ induces a marked depression of thyroid hormones [14, 26, 27]. Researchers have found that low T3 [28] or T4 [14] levels were correlated with postoperative morbidity in open heart surgery with $\mathrm{CPB}$. A study was conducted to assess the effects of $\mathrm{CPB}$ on thyroid function in infants weighing less than $5 \mathrm{~kg}$, and the results showed 
Table $\mathbf{2}$ Characteristics of patients according to survivors and non-survivors

\begin{tabular}{|c|c|c|c|}
\hline Characteristic & $\begin{array}{l}\text { Survivors } \\
(N=120)\end{array}$ & $\begin{array}{l}\text { Non-survivors } \\
(N=13)\end{array}$ & $P$ value \\
\hline Age (days) & $38.63 \pm 26.87$ & $17.46 \pm 17.10$ & 0.006 \\
\hline$\leq 28$ days & $41(34.1 \%)$ & $9(69.2)$ & 0.017 \\
\hline Female & $44(36.7 \%)$ & $0(0 \%)$ & 0.005 \\
\hline Weight (kg) & $3.92 \pm 0.93$ & $3.61 \pm 0.63$ & 0.234 \\
\hline RACHS- $1 \geq 4$ & $31(25.8 \%)$ & $8(61.5 \%)$ & 0.020 \\
\hline Preoperative serum albumin (g/L) & $38.13 \pm 4.97$ & $39.31 \pm 3.78$ & 0.406 \\
\hline \multicolumn{4}{|l|}{ Preoperative thyroid function } \\
\hline FT3 (pmol/L) & $5.11 \pm 1.55$ & $3.91 \pm 0.99$ & 0.007 \\
\hline FT4 (pmol/L) & $21.52 \pm 5.79$ & $19.02 \pm 5.85$ & 0.142 \\
\hline TT3 (nmol/L) & $1.90 \pm 0.57$ & $1.55 \pm 0.35$ & 0.032 \\
\hline TT4 (nmol/L) & $122.07 \pm 34.77$ & $103.47 \pm 29.10$ & 0.066 \\
\hline TSH ( $\mu \mid \mathrm{U} / \mathrm{ml})$ & $5.48 \pm 4.94$ & $7.89 \pm 11.90$ & 0.483 \\
\hline \multicolumn{4}{|l|}{ Operative factors } \\
\hline CPB time (min) & $111.53 \pm 83.87$ & $139.07 \pm 58.61$ & 0.251 \\
\hline ACC time (min) & $45.01 \pm 21.61$ & $55.40 \pm 19.73$ & 0.100 \\
\hline
\end{tabular}

Abbreviations as in Table 1

that low T3 and T4 levels were both predictors of high mortality [13]. Since low postoperative low levels of thyroid hormones could lead to a poor prognosis, a preoperative increase in thyroid hormones may improve the prognosis. A multicenter randomized controlled trial (RCT) of T3 supplementation of patients undergoing heart surgery with CPB (TRICC) showed that T3 supplementation provides clinical advantages in patients younger than 5 months, but not in older patients [29]. Talwar et al. [10] performed an RCT study of perioperative oral T4 in patients younger than 6 months who underwent open heart surgery with $\mathrm{CPB}$ and found that postoperative thyroid hormone levels were reduced and that T4 supplementation reduced the duration of $\mathrm{MV}$ and ICU and hospital stays. Therefore, the preoperative level of thyroid hormones may predict the prognosis of patients with CHD undergoing CPB. Kumar et al. [30] found that low T3 is an important marker of mortality in critically ill patients, while low T4 and TSH levels did not increase the predictability of mortality. A large-scale prospective, observational study of unselected ICU patients, found that FT3 was the most powerful and independent predictor of ICU mortality among the thyroid hormone indicators [16]. However, Quispe et al. [31] found that the FT3 level was not significantly different between survivors and non-survivors and was not a mortality predictor. This might have occurred because previous studies did not consider the relationship of FT3 with

Table 3 Multivariate logistic regression, odds ratio of variables for predicting ICU mortality in patients with congenital heart disease after cardiopulmonary bypass

\begin{tabular}{|c|c|c|c|c|c|c|c|c|}
\hline \multirow[t]{2}{*}{ Variables } & \multirow[t]{2}{*}{ B } & \multirow[t]{2}{*}{ S.E. } & \multirow[t]{2}{*}{ Wald } & \multirow[t]{2}{*}{ df } & \multirow{2}{*}{$\begin{array}{l}P \\
\text { value }\end{array}$} & \multirow[t]{2}{*}{ OR } & \multicolumn{2}{|c|}{$95 \%$ C.I. for OR } \\
\hline & & & & & & & Lower & Upper \\
\hline Age & -0.036 & 0.016 & 3.406 & 1 & 0.065 & 0.965 & 0.929 & 1.002 \\
\hline RASCH-1 $\geq 4$ & -1.002 & 0.528 & 1.621 & 1 & 0.203 & 0.367 & 0.078 & 1.717 \\
\hline ACC & -0.003 & 0.016 & 0.038 & 1 & 0.846 & 0.997 & 0.966 & 1.028 \\
\hline FT3 & -1.112 & 0.528 & 4.429 & 1 & 0.035 & 0.329 & 0.117 & 0.926 \\
\hline TT3 & 2.227 & 1.437 & 2.400 & 1 & 0.121 & 9.268 & 0.554 & 155.017 \\
\hline ТT4 & -0.017 & 0.012 & 2.121 & 1 & 0.145 & 0.983 & 0.960 & 1.006 \\
\hline Constant & 2.560 & 1.693 & 2.286 & 1 & 0.131 & 12.937 & & \\
\hline
\end{tabular}

Abbreviations as in Table 1 


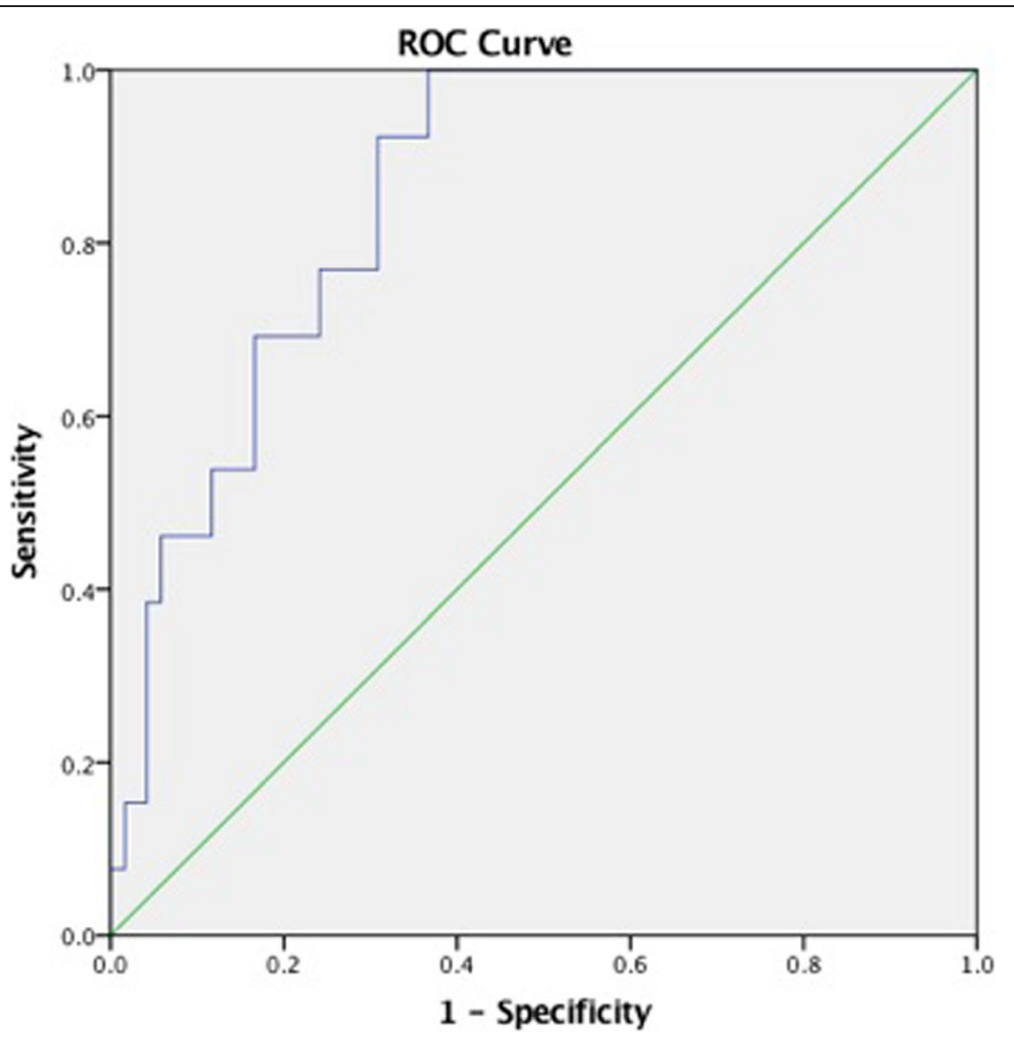

Fig. 1 Receiver operating characteristic curves for free triiodothyronine (FT3)

albumin as confounding factor, and when hypoalbuminemia was present, conversion of T4 to T3 was decreased, resulting the low FT3 levels [32]. However, there was no significant difference in the preoperative albumin level between survivors and non-survivors in our study. Additionally, acute critically ill patients release large mounts of other hormones, such as cortisol, which has an inhibitory effect on TSH and eventually leads to low T3 levels [33]. In our study, patients were not in stress states and had similar preoperative albumin levels, and with the exclusion of these two confounding factors, we found that the preoperative FT3 level may be a predictor of ICU mortality after $\mathrm{CPB}$ in infants with CHD younger than 3 months old.

Our study showed that FT3 is an independent predictor of ICU mortality because of its high AUC value. Thyroid hormones include $\mathrm{T} 4$, which represents the major form of circulating thyroid hormones (> $80 \%)$, and T3, which accounts for a small portion $(<20 \%)$ of circulating thyroid hormone and has a major biological effect on the heart. Moreover, the levels of TT3 and TT4 levels can be affected by the thyroxine-binding globulin (TBG) concentration or the binding ability of TBG, which may be affected by several drugs, including furosemide and heparin [16]. In contrast, FT3 and FT4 were not affected by these conditions. Thus, the FT3 level may be a better predictor of ICU mortality than other thyroid hormones, which is consistent with our findings.

Some limitations exist in our study. First, this was a retrospective study with a small sample size, which limited the statistical power. Therefore, additional patients need to be enrolled, and a prospective randomized multicenter study should be conducted. Second, patients with RACHS- 1 scores of 5 or 6 are rare, which reduced the ability of the RACHS- 1 to predict ICU mortality in children with CHD. Finally, in a

Table 4 Value of FT3 in predicting ICU morality

\begin{tabular}{llllll}
\hline Variable & AUC & P valve & Cutoff value & Sensitivity (\%) & Specificity (\%) \\
\hline FT3 & $0.856 \pm 0.040$ & 0.000 & 4.89 & 100 & 63.3 \\
\hline
\end{tabular}


retrospective study, it is difficult to collect data on perioperative and postoperative dopamine levels and steroid use; thus, we did not consider the relationship of thyroid hormones with dopamine and steroids, which may provide more robust evidence to assess the predominant predictor.

\section{Conclusions}

The preoperative FT3 level may be a powerful and independent predictor of ICU mortality after CPB in infants with CHD who are younger than 3 months old.

\begin{abstract}
Abbreviations
ACC: Aortic Cross-Clamping; AUC: Area Under the Curve;

CPB: Cardiopulmonary Bypass; CHD: Congenital Heart Disease; FT3: Free Triiodothyronine; FT4: Free Thyroxin; ICU: Intensive Care Unit; MV: Mechanical Ventilation; RACHS-1: Risk Adjustment in Congenital Heart Surgery-1; RCT: Randomized Controlled Trial; ROC: Receiver Operating Characteristic; TBG: Thyroxine-Binding Globulin; T3: Triiodothyronine; T4: Thyroxin; TT3: Total Triiodothyronine; TT4: Total Thyroxin; TSH: Thyroid Stimulating Hormone
\end{abstract}

\section{Acknowledgements}

None declared.

\section{Author contributions}

X.M.M. and Y.O.S. designed the study. D.Y. and L.Z. wrote the manuscript D.Y., L.Z. and Y.S.C. collected the data, and Y.P.L. and Q.F.W. analyzed the data. All authors reviewed the manuscript.

\section{Funding}

X.M.M. received funding from the National Natural Science Foundation of China (81370277), and Clinical Frontier Technology of Clinical Medicine of Jiangsu Provincial Science and Technology Department (BE2017608). D.Y. received funding from the National Natural Science Foundation of China the Science (81700288), Science and Technology Development Fund Key Project of Nanjing Medical University (2016NJMUZD055), Science and Technology Development Project of Nanjing (YKK17162) and Social Development Project of Nanjing (201805001). The funders had no role in the study design, data collection and analysis, decision to publish or preparation of the manuscript.

\section{Availability of data and materials}

The datasets used in current study are available from the corresponding author on reasonable request.

\section{Ethics approval and consent to participate}

Study approval and ethical clearance were obtained from the Institutional Ethical Committees of Children's Hospital of Nanjing Medical University (201912257-1). No administrative permissions and/or licenses were acquired by our team to access the data used in our research.

\section{Consent for publication}

Not applicable.

\section{Competing interests}

The authors declare that they have no potential conflicts of interest with respect to the research, authorship and/or publication of this article.

Received: 16 September 2020 Accepted: 19 January 2021

Published online: 25 January 2021

\section{References}

1. Dolk H, Loane M, Garne E. European Surveillance of Congenital Anomalies (EUROCAT) Working Group. Congenital heart defects in Europe: prevalence and perinatal mortality, 2000 to 2005. Circulation. 2011;123(8):841-9.

2. van der Linde D, Konings EE, Slager MA, Witsenburg M, Helbing WA, Takkenberg JJ, Roos-Hesselink JW. Birth prevalence of congenital heart disease worldwide: a systematic review and meta-analysis. J Am Coll Cardiol. 2011;58(21):2241-7.
3. Holland FW, Brown PS, Weintraub BD, Clark RE. Cardiopulmonary bypass and thyroid function: a "euthyroid sick syndrome". Ann Thorac Surg. 1991; 52(1):46-50.

4. Lerner RK, Gruber N, Pollak U. Congenital Heart Disease and Thyroid Dysfunction: Combination, Association, and Implication. World J Pediatr Congenit Heart Surg. 2019;10(5):604-15.

5. Dimmick S, Badawi N, Randell T. Thyroid hormone supplementation for the prevention of morbidity and mortality in infants undergoing cardiac surgery. Cochrane Database Syst Rev. 2004;3:CD004220.

6. Danzi S, Klein I. Thyroid hormone and the cardiovascular system. Med Clin North Am. 2012;96(2):257-68.

7. Klein I, Danzi S. Thyroid disease and the heart. Circulation. 2007;116(15): 1725-35.

8. Lynch BA, Brown DM, Herrington C, Braunlin E. Thyroid dysfunction after pediatric cardiac surgery. J Thorac Cardiovasc Surg. 2004;127(5):1509-11.

9. Kuwata S, Takanashi M, Hashimoto M, Iwamoto Y, Ishido H, Masutani S, Saiki $\mathrm{H}$, Sugamoto K, Senzaki H. Thyroid Function in Patients With a Fontan Circulation. Am J Cardiol. 2019;123(6):979-83.

10. Talwar S, Bhoje A, Khadagawat R, Chaturvedi P, Sreenivas V, Makhija N, Sahu M, Choudhary SK, Airan B. Oral thyroxin supplementation in infants undergoing cardiac surgery: A double-blind placebo-controlled randomized clinical trial. J Thorac Cardiovasc Surg. 2018;156(3):1209-7.e3.

11. Marwali EM, Boom CE, Budiwardhana N, Fakhri D, Roebiono PS, Santoso A Sastroasmoro S, Slee A, Portman MA. Oral Triiodothyronine for Infants and Children Undergoing Cardiopulmonary Bypass. Ann Thorac Surg. 2017; 104(2):688-95.

12. Marwali EM, Caesa P, Darmaputri S, Sani AA, Roebiono PS, Fakhri D, Djer MM, Munasir ZM, Batubara JRL, Satroasmoro S, Portman MA, Haas NA. Oral Triiodothyronine Supplementation Decreases Low Cardiac Output Syndrome After Pediatric Cardiac Surgery. Pediatr Cardiol. 2019;40(6):123846.

13. Mitchell IM, Pollock JC, Jamieson MP, Donaghey SF, Paton RD, Logan RW. The effects of cardiopulmonary bypass on thyroid function in infants weighing less than five kilograms. J Thorac Cardiovasc Surg. 1992;103(4): 800-5.

14. Talwar S, Khadgawat R, Sandeep JA, Sreenivas V, Choudhary SK, Gupta N, Airan B. Cardiopulmonary bypass and serum thyroid hormone profile in pediatric patients with congenital heart disease. Congenit Heart Dis. 2012; 7(5):433-40.

15. Jenkins KJ, Gauvreau K, Newburger JW, Spray TL, Moller JH, lezzoni LI. Consensus-based method for risk adjustment for surgery for congenital heart disease. J Thorac Cardiovasc Surg. 2002;123(1):110-8.

16. Wang F, Pan W, Wang H, Wang S, Pan S, Ge J. Relationship between thyroid function and ICU mortality: a prospective observation study. Crit Care. 2012;16(1):R11.

17. Vasdev S, Chauhan S, Malik M, Talwar S, Velayoudham D, Kiran U. Congenital heart surgery outcome analysis: Indian experience. Asian Cardiovasc Thorac Ann. 2013;21 (6):675-82

18. Geier L, Menzel C, Germund I, Trieschmann U. RACHS-1 score as predictive factor for postoperative ventilation time in children with congenital heart disease. Cardiol Young. 2020;30(2):213-8.

19. Al-Radi OO, Harrell FE, Caldarone CA, McCrindle BW, Jacobs JP, Williams MG, Van Arsdell GS, Williams WG. Case complexity scores in congenital heart surgery: a comparative study of the Aristotle Basic Complexity score and the Risk Adjustment in Congenital Heart Surgery (RACHS-1) system. J Thorac Cardiovasc Surg. 2007:133(4):865-75.

20. Bobillo-Perez S, Sanchez-de-Toledo J, Segura S, Girona-Alarcon M, Mele M, Sole-Ribalta A, Cañizo Vazquez D, Jordan I, Cambra FJ. Risk stratification models for congenital heart surgery in children: Comparative single-center study. Congenit Heart Dis. 2019;14(6):1066-77.

21. Cavalcante CT, de Souza NMG, Pinto VC, Branco KM, Pompeu RG, Teles AC, Cavalcante RC, de Andrade GV. Analysis of Surgical Mortality for Congenital Heart Defects Using RACHS-1 Risk Score in a Brazilian Single Center. Braz J Cardiovasc Surg. 2016;31(3):219-25.

22. Mussino E, Miranda V, Ma L. Changes in sex ratio at birth among immigrant groups in Sweden. Genus. 2018;74(1):13

23. Wang X, Nie W, Liu P. Son Preference and the Reproductive Behavior of RuralUrban Migrant Women of Childbearing Age in China: Empirical Evidence from a Cross-Sectional Data. Int J Environ Res Public Health. 2020;17(9):3221.

24. Chowdhury D, Parnell VA, Ojamaa K, Boxer R, Cooper R, Klein I. Usefulness of triiodothyronine (T3) treatment after surgery for complex congenital heart disease in infants and children. Am J Cardiol. 1999;84(9):1107-9. 
25. Zhang JQ, Yang QY, Xue FS, Zhang W, Yang GZ, Liao X, Meng FM. Preoperative oral thyroid hormones to prevent euthyroid sick syndrome and attenuate myocardial ischemia-reperfusion injury after cardiac surgery with cardiopulmonary bypass in children: A randomized, double-blind, placebo-controlled trial. Medicine. 2018;97(36):e12100.

26. Cantinotti M, Lorenzoni V, Storti S, Moschetti R, Murzi B, Marotta M, Crocetti M, Molinaro S, Clerico A, Portman M, lervasi G. Thyroid and brain natriuretic Peptide response in children undergoing cardiac surgery for congenital heart disease-age-related variations and prognostic value. Circ J. 2013;77(1): 188-97.

27. Cruz PM, Bello CN, Marcial ML, Auler Junior JO. Thyroid function profile in infants submitted to cardiac surgery with cardiopulmonary bypass. Rev Bras Anestesiol. 2004;54(3):325-34.

28. Bettendorf M, Schmidt KG, Tiefenbacher U, Grulich-Henn J, Heinrich UE, Schonberg DK. Transient secondary hypothyroidism in children after cardiac surgery. Pediatr Res. 1997;41(3):375-9.

29. Portman MA, Slee A, Olson AK, Cohen G, Karl T, Tong E, Hastings L, Patel H, Reinhartz O, Mott AR, Mainwaring R, Linam J, Danzi S, TRICC Investigators. Triiodothyronine Supplementation in Infants and Children Undergoing Cardiopulmonary Bypass (TRICC): a multicenter placebo-controlled randomized trial: age analysis. Circulation. 2010;122(11 Suppl):224-33.

30. Kumar KV, Kapoor U, Kalia R, Chandra NS, Singh P, Nangia R. Low triiodothyronine predicts mortality in critically ill patients. Indian J Endocrinol Metab. 2013;17(2):285-8.

31. Quispe E, Li XM, Yi H. Comparison and relationship of thyroid hormones, IL6, IL-10 and albumin as mortality predictors in case-mix critically ill patients. Cytokine. 2016;81:94-100.

32. Nicholson JP, Wolmarans MR, Park GR. The role of albumin in critical illness. Br J Anaesth. 2000;85(4):599-610.

33. Karga H, Papaioannou P, Venetsanou K, Papandroulaki F, Karaloizos L, Papaioannou G, Papapetrou P. The role of cytokines and cortisol in the nonthyroidal illness syndrome following acute myocardial infarction. Eur J Endocrinol. 2000;142(3):236-42.

\section{Publisher's Note}

Springer Nature remains neutral with regard to jurisdictional claims in published maps and institutional affiliations.

Ready to submit your research? Choose BMC and benefit from:

- fast, convenient online submission

- thorough peer review by experienced researchers in your field

- rapid publication on acceptance

- support for research data, including large and complex data types

- gold Open Access which fosters wider collaboration and increased citations

- maximum visibility for your research: over $100 \mathrm{M}$ website views per year

At $\mathrm{BMC}$, research is always in progress.

Learn more biomedcentral.com/submissions 